\title{
Kebudayaan Islam yang Berkembang di Kesultanan Bima pada Abad Ke XVII M
}

\author{
Zuriatin $^{1}$, Nurhasanah ${ }^{2}$ \\ ${ }^{1}$ STKIP Taman Siswa Bima \\ ${ }^{2}$ STKIP Bima \\ 12atinamin57@gmail.com
}

\begin{abstract}
ABSTRAK
Masuk dan berkembangnya Islam di Bima tidak hanya membawa perubahan besar pada kepercayaan yang di anut oleh masyarakat di kerajaan tersebut namun juga membawa perubahan secara-besaran terhadap tatanan politik, sosial dan kemasyarakatan serta kebudayaan. Pengaruh Islam terlihat nyata pada kebudayaan yang berkembang sesudah agama ini mulai tumbuh dan berkembang di Bima. Perpaduan antara kebudayaan Islam dan kebudayaan local terjalin indah dalam setiap adat dan budaya yang berkembang dalam masyarakat. hal ini terlihat dari berbagai kebudayaan antaa lain; pertama "Rimpu" yang merupakan busana adat harian tradisional yang berkembang pada masa kesultanan Bima. Sebagai pakaian yang mencerminkan identitas wanita Bima yang sesuai dengan ajaran agama Islam. Upacara memperingatan mauled nabi besar Muhammad SAW di oleh masyarakat Bima di adakan acara Hanta Ua pua. Ketiga Zikir (jiki) kepada Allah yang di lantunkan pada suklus hidup masyarakat. Keempat Hadrah: Merupakan tari tradisional Bima yang berisi puji-pujian kepada Allah SWT. Kelima Dali merupakan Puisi yang di sebut "dali" ini dapat juga di sebut dalil yaitu suatu petuah dan nasehat yang berdasar atas adat dan agama. Keenam Acara khitan dan Khatam Al-qur'an Dalam adat Bima, proses pendewasaan seorang anak manusia ditandai dengan dua macam upacara adat. Upacara adat ini merupakan pengejawantahan syariat Islam yaitu kewajiban untuk melaksanakan khitan bagi laki-laki serta anjuran untuk menamatkan pembelajaran baca Al-Qur'an sebagai penuntun hidup seorang manusia untuk mendapatkan kebahagiaan dunia dan akhirat
\end{abstract}

Kata kunci: Kebudayaan, Islam, Kesultanan Bima

\section{PENDAHULUAN}

Kedatangan agama Islam pada Abad ke -7 M ke dunia di anggap sebagai pembangun Dunia Baru, cita-cita baru, kebudayaan serta peradaban baru. (Sunanto : 2006 hal 1). Islam masuk di Indonesia pada Abad ke XIII dan berkebang di hampir seluruh wilayah Nusantara pada abad ke XVII M. lalu kemudian membentuk kesultanankesultanan Baru yang nantinya di tiap wilayah kesultanan tersebut tercipta suatu kebudayaan dan tradisi baru yang bernafaskan Islam.

kehadiran Islam di berbagai daerah di Indonesia tidak saja membawa pengaruh pada segi akidah dan kepercayaan semata namun juga membawa pengaruh yang sangat besar terhadap perkembangan social kebudayaan masyarakat setempat. Tak jarang kehadiran islam di suatu daerah juga memciptakan suatu budaya dan tradii baru yang menjadi identitas daerah tersebut.

Islam masuk dan berkembang di Kerajaan Bima pada abad ke XVII M. disebutkan dalam kitab BO Sanggaji Kai Bahwa telah datang pedagang-pedagang dari Gowa-Tallo, Luwu dan Bone membawa Agama Islam dan berlabuh di pelabuhan Sape pada tahun 1028 H (1618 M). kemudian pada tahun $1030 \mathrm{H}$ (1621 M) Agama Islam diterima sebagai agama resmi kerajaan yang ditandai dengan pengislaman La Kai putra mahkota kerajaan Bima. (Majid : 2007 hal 89)

Putra Mahkota La Kai setelah memeluk Islam berganti nama menjadi Abdul Kahir. Beliau merupakan sultan pertama di kerajaan Bima. Setelah islam menjadi agama resmi maka secara resmi status kerajaan beralih menjadi kesultanan dan raja-raja berikutnya beralih gelar 
menjadi sultan yang kemudian di wariskan secaa turun temurun hingga sultan ke 26 yang memerintah hingga masa-masa awal kemerdekaan Indonesia.

Dengan peralihan politik dan pemerintahan yang sebelumnya berentuk kerajaan yang bercorak hindu kemudian beralih menjadi kesultanan yang bercorak Islam secara otomatis membawa dampak yang besar bagi perkembangan kehidupan bermasyarakat dan bernegara. Perubahan pertama; yang Nampak terjadi pada masyarakat yaitu konversi kepercayaan dan keyakinan yang sebelumnya menganut hindu dan sebagian masih menganut animisme dan dinamisme kemudian berubah menjadi seorang muslim. Islam setelah di anut oleh penguasa yaitu Sultan Abdul Kahir dan para pembesar istana kemudian di ikuti secara massal oleh rakyat hal ini sesui dengan teori penerimaan Islam di berbagai wilayah di Indonesia yaitu teori Top down dimana Islam diterima langsung oleh elit penguasa kerajaan lalu kemudian di sosialisasikan dan berkembang ke masyarakat bawah. ( Sewang. 2005, hal; 86)

Di berbagai tempat yang di singgahi Islam telah menjadi suatu kesimpulan umum jika raja memeluk satu keyakinan maka seluruh rakyat akan mengikuti keyakinan tersebut. Perubahan yang kedua yaitu perubahan tata laksana pemerintahan yang sesuai dengan syariat islam. Perubahan yang ketiga; yaitu adanya perubahan kebudayaan dan social kemasyarakatan.

Setelah islam masuk dan berkembang di kesultanan Bima adat istiadat yang berkaitan dengan daur hidup disesuaikan dengan ajaran agama Islam meskipun tradisi pra Islam tetap di pertahankan namun juga disisipkan nilaanilai yang terkandung dalam ajaran islam.

\section{Kajian Pustaka}

Peradaban Islam adalah terjemahan dari kata Arab Al-Hadra-Rah Al-Islamiyyah. Kata ara ini sering juga di terjemahkan kedalam bahasa
Indonesia dengan kebudayaan Islam. "kebudayaan" dalam bahasa Arab adalah AlTsaqafah. Di Indonesia sebagai mana juga di Arab dan Barat, masih banyak orang yang mensinonimkan dua kata "kebudayaan" (Arab, al-tsaqafah ; Inggris , Culture) dan peradaban ( Arab al-hadra-rah; Inggris, civilization). Dalam perkembangan ilmu antropologi sekarang, kedua istilah tersebut di bedakan. Kebudayaan adalah bentuk ungkapan tentang semangat mendalam suatu masyarakat. sedangkan manifestasi-manifestasi kemajuan mekanis dan teknologi lebih berkaitan dengan peradaban. Kalau kebudayaan lebih banyak direfleksikan dalam seni, sastra, religi (agama) dan moral, maka peradaban terefleksi dalam politik ekonomi dan teknologi. ( Effat Al-Sharqawi. 1986 hal 5)

Secara etimologis kebudayaan berasal dari bahasa Sansekerta "budhayah", yaitu bentuk jamak dari budhi yang berarti budi atau akal. Sedangkan ahli antropologi yang memberikan definisi tentang kebudayaan secara sistematis dan ilmiah adalah E.B. Tylor dalam buku yang berjudul "Primitive Culture", bahwa kebudayaan adalah keseluruhan kompleks yang di dalamnya terkandung ilmu pengetahuan lain, serta kebiasaan yang didapat manusia sebagai anggota masyarakat. Pada sisi yang agak berbeda, Koentjaraningrat mendefinisikan kebudayaan sebagai keseluruhan manusia dari kelakuan dan hasil kelakuan yang teratur oleh tata kelakuan yang harus didapatkanya dengan belajar dan yang semuanya tersusun dalam kehidupan masyarakat. Dari beberapa pengertian tersebut dapat ditarik kesimpulan bahwa kebudayaan adalah keseluruhan sistem gagasan, tindakan, dan hasil karya manusia untuk memenuhi kehidupannya dengan cara belajar, yang semuanya tersusun dalam kehidupanan masyarakat. 
Secara lebih jelas dapat diuraikan sebagai berikut: 1). Kebudayaan adalah segala sesuatu yang dilakukan dan dihasilkan manusia, yang meliputi: a). kebudayaan materiil (bersifat jasmaniah), yang meliputi benda-benda ciptaan manusia, misalnya kendaraan, alat rumah tangga, dan lain-lain. b) Kebudayaan nonmateriil (bersifat rohaniah), yaitu semua hal yang tidak dapat dilihat dan diraba, misalnya agama, bahasa, ilmu pengetahuan, dan sebagainya. 2). Kebudayaan itu tidak diwariskan secara generatif (biologis), melainkan hanya mungkin diperoleh dengan cara belajar. 3). Kebudayaan diperoleh manusia sebagai anggota masyarakat. Tanpa masyarakat kemungkinannya sangat kecil untuk membentuk kebudayaan. Sebaliknya, tanpa kebudayaan tidak mungkin manusia (secara individual maupun kelompok) dapat mempertahankan kehidupannya. Jadi, kebudayaan adalah hampir semua tindakan manusia dalam kehidupan sehari-hari. (koentaraningrat. 1992 hal 29)

Pengertian Islam menurut kamus ilmiah popular adalah damai tenteram, agama yang di bawa oleh Nabi Muhammad SAW dengan kitab suci Al'Qur'an. Sedangkan Islamisasi adalah pengislaman dunia, usaha mengislamkan dunia. Sedangkan Menurut ricklefs Islamisasi adalah suatu proses yang tidak terhenti yakni sejak datangnya Islam pertama kali, penerimaan dan penyebaran lebih lanjut hingga saat ini. (ricklefs. 1981)

Berdasarkan beberapa pendapat ahli di atas maka kebudayaan Islam yang di maksudkan dalam penelitian ini yaitu kebudayaan yang berasal dari pengaruh masuknya Islam di Bima yang terefleksi dalam seni, sastra, religi (agama) dan moral yang berkembang pada masyarakat Bima yang kemudian menjadi ciri yang tidak dapat terpisahkan dari masyarakat tersebut.

\section{Tujuan Penelitian}

Tujuan penelitian ini yaitu untuk mengetahup perkembagan kebudayaan dan kesenian pada masa kesultanan Bima abad ke XVII.

\section{METODE PENELITIAN}

Jenis penelitian ini adalah penelitian sejarah yang berpangkal pada masa lampau Penelitian ini menggunakan pendekatan Tekstual yaitu Penelitian dengan menggunakan Arsip, Proses penelitian ini berfokus pada masa lampau, yang akan dilaksanakan dengan metode sejarah, yaitu proses menguji dan menganalisis secaa kritis rekaman dan peninggalan masa lampau berdasarkan data yang di peroleh. (Lois Gottschalk. hal 39 :2008). dalam hal ini peneliti berusaha menguraikan tentang perkembangan kebudayaan dan tradisi Islam pada masa kesultanan Bima. Adapun metode penelitian yang di gunakan yaitu metode penelitian sejarah yang terdiri dari empat tahapan yaitu 1). Heurustik 2). Kritik, 3). Interpretasi, 4). Historiografi.

Langkah pertama yaitu heuristic (pengumpulan sumber). Heuristic merupakan keterampilan untyk mengumpulkan sumber. Penulis mengumpulkan sumber-sumber baik tertulis maupun lisan yang sesuai dengan tema penelitian. Sumber di peroleh dari buku, jurnal laporan penelitian, internet maupun sumbersumber lain yang sesuai dengan tema penelitian. Sumber lain yang di pergunakan untuk melengkapi sumber pustaka yaitu sumber lisan dimana penelusuran data denan melakukan wawancara terhadap tokoh masyarakat atau pelaku budaya yang masih mempertahankan kebudayaan islam di Bima.

Langkah kedua yaitu verifikasi (kritik sumber). Metode ini adalah dengan melakukan kritik terhadap sumber yang penulis peroleh. Dalam ktitik sumber ada 2 macam kritik yang harus di lakukan yaitu ; 1). Keaslian sumber (otentitas) yang dilakukan melalui kritik eksteren. Kritik di lakukan untuk menguji 
bagian fisik sumber yang didapatkan dan keakuratan sumber. 2) keabsahan tentang kebenaran sumber (kredibilitas) pada tahap ini penulis membandingkan sumber yang satu dengan sumber yang lainuntuk mencari data yang lebih akurat yang berkaitan dengan tema penelitian

Langkah ketiga yaitu interpretasi ( analisis fakta sejarah) interpretasi merupakan proses pengabungan atas sjumlah fakta yang di peroleh dari sumber-sumber sejarah yang berkaitan dengan tema penelitian dan dengan sebuah teori kemudian disusunlah fakta tersebut ke dalam suatu interpretasi secara menyeluruh. Setelah data penelitian ini di peroleh dari pustaka dan wawancara maka dipergunakan teori budaya islam dalam melukiskan perkembangan kebudayaan islam di bima yang masih bertahan hingga sekarang.

Langkah keempat adalah historiografi (penulisan sejarah). Sebagai langkah yang terakhir dalam metode sejarah, historiografi merupakan cara penulisan sejarah, pemaparan atau pelaporan hasil penelitian yang telah di laksanakan ( Dudung Abdurahman. hal 117: ) setelah semua langkah telah di lakukan yang meliputi kegiatan pengumpulan sumber, kritik terhadap sumber data dan analisis data telah di laksanakan maka langkah terakhir yaitu melakukan penulisan dan penyajian secara utuh dan sistematis atas perkembangan kebudayaan islam di kesultanan Bima.

Sumber Data

Adapun sumber data yang di gunakan dalam penelitian ini adalah a). Data primer yaitu data yan di peroleh dari arsip-arsip yang baik terdapat pada kantor-kantor terkait maupun arsip-arsip yang di simpan perorangan yang dapat menunjang tulisan ini. Seperti: arsip-arsip yang terdapat pada museum Asi Mbozo, Samparaja dan arsip lepas yang ada pada Sekretaris Majelis Hadat dana Mbojo. Bo Sanggaji Kai. b). Data sekunder yaitu berupa bahan tertulis yang di peroleh melalui buku-buku, makalah, artikelartikel ilmiah maupun catatan-catatan lepas yang ada hubungannya dengan tulisan ini. Dan wawancara dengan tokoh adat Bima

\section{HASIL DAN PEMBAHASAN Rimpu}

Rimpu merupakan busana adat harian tradisional yang berkembang pada masa kesultanan Bima. Sebagai pakaian yang mencerminkan identitas wanita Bima. Jenis pakaian ini hanya bisa kita jumpai pada masyarakat Bima. Keberadaan rimpu pada wanita Bima tidak terlepas dari masuk dan berkembangnya Islam di Bima. Keberadaan para pedagang dan mubalik dari Arab menjadi salah satu sumber bagi wanita Bima untuk mengidentikkan pakaian orang Arab tersebut dengan menggunakan rimpu. (Siti Lamusiah. 2013. Hal 18)

Keberadaan Rimpu tidak lepas dari upaya pemerintah dalam memanfaatkan kain sarung atau kain tenun yang di produksi sendiri oleh wanita Bima. Sejak zaman kesultanan bagi wanita yang telah akil baliq di wajibkan untuk memakai rimpu apabila hendak keluar rumah dan bepergian. Jika tidak mengunakan rimpu dapat di katakana wanita tersebut telah melangar hukum agama dan adat yang berlaku dalam masyarakat saat itu. Hukuman yang di peroleh berupa hukuman moral dan menjadi bahan perbincangan dalam masyarakat.

Bagi masyarakat Bima pada masa lalu pemakaian rimpu merupakan identitas dan cerminan ketakwaan seorang wanita terhadap agama dan norma sosial dalam masyarakat. bagi wanita Bima pada masa lampau memandang tersingkapnya aurat mereka sebagai aib.

Rimpu merupakan pakaian yang terdiri dari dua lembar sarung yang di pergunakan untuk menutup aurat dari kepala hingg kaki. Lembar pertama di pakai untuk menutup kepala satu lembar lagi di pergunakan untuk bawahan sama seperti pengunaan sebagai rok. rimpu sendiri di bedakan menjadi tiga macam disesuaikan dengan status pemakainya yang pertama Rimpu Cili atau rimpu mpida di pakai oleh gadis yang 
belum bersuami di mana seluruh tubuh tertutup oleh sarung yang terlihat hanya bagian mata saja sama seperti cadar di masa sekarang. jenis yang kedua yaitu "rimpu colo" atau di beberapa desa di sebut juga "saleko" di pergunakan oleh kaum ibu di mana seluruh muka di biarkan terlihat sama seperti jilbab sekarang. Cara memakai rimpu yaitu sarung pertama dililt memutar mengikuti arah kepala dan muka lalu bagian mata atau seluruh muka di biarkan terbuka. Sarung kedua dililitkan pada bagian perut sehingga membentuk seperti rok lalu ditangkupkan atau di semat pada bagian kanan dan kiri pinggang. Perbedaan pengunaan rimpu pada wanita Bima secara tidak langsung menjelaskan status wanita yang masih boleh di nikahi atau tidak. Rimpu selain sebagai pakaian sehari wanita Bima juga merupakan representasi ahlak dan moral yang bersendikan nilai-nilai Islam dalam kehidupan masyarakat Bima.

\section{Hanta ua pua}

Ua Pua dalam bahasa Melayu "Sirih Puan " adalah satu rumpun "tangkai bunga telur" berwarna-warni yang jumlahnya sebanyak 99 tangkai melambangkan asmaul husna. Bunga telur di tempatan dalam wadah bersegi empat dan di tenggah-tenggahnya ada sebuah Al-Quran.

Ua Pua ini di tempatkan di tengah-tengah rumah mahligai (uma lige) yang berbentuk segi empat berukuran $4 \times 4 \mathrm{M}^{2}$. Bentuk uma lige in terbuka dari keempat sisinya. Atapnya tersusun dua. Sehingga masyarakat yang berada di sepanjang jalan dapat melihat penghulu melayu dan pengikutnya serta para penari lenggo Melayu yang terdiri dari empat orang laki-laki dan lenggo mbojo yang terdiri daru empat orang gadis berada di atas uma lige.

Uma Lige di usung oleh 44 orang pria yang berbadan kekar sebagai symbol dari keberadaan 44 DARI MBOJO yang terbagi menurut 44 jenis keahlian dan keterampilan yang dimiliki sebagai bagian dari struktur pemerintahan kesultanan
Bima. Rombongan dan usungan uma lige memulai perjalanan dari kampong melayu menuju ke Istana Kesultanan Bima untuk di terima oleh sultan Bima dengan amanah yang harus di kerjakan yaitu memegang teguh ajaran Islam.

Sebelum acara inti upacara adat "hanta ua pua" dilaksanakan di istana kesultanan Bima, pada tanggal 12 Rabiul awal malam diselengarakan Dzikir Maulud di istana yang diikuti oleh Majelis Adat Dana Mbojo, pejabat pemerintah serta masyarakat umum. Dzikir ini diadakan untuk memperingati hari Maulud Nabi Besar Muhammad SAW. Sembari Dzikir berlangsung oleh beberapa orang dilakukan pengirisan daun pandan untuk membuat "Bunga Bareka" yaitu pandan yang di campur dengan berbagai macam kembang dan wangiwangian yang akan dibagikan kepada para peserta dzikir dan tamu undangan.

Pada awalnya upacara Ua Pua merupakan salah satu bentuk Islamisasi atau penanaman Nilai-nilai keislaman yang belum kuat di Bima pada masa sultan kedua oleh para ulama. Uapacara ua pua di pertama kali di rintis oleh Datuk Raja Lelo, Datuk Iskandar, Datuk Selangkote, Datuk Lela, Datuk Panjang, kelima ulama tersebut berasal dari Minangkabau merupakan anak keturunan dari Datuk di Banda dan Datuk Di Tiro yang merupakan guru dari Sultan Bima yang pertama Sultan Abdul Kahir. Kelima ulama tersebut datang ke Bima untuk menruskan kegiatan dahwah yang telah di ritis oleh Datuk di Banda dan Datuk Di Tiro kerena kedua ulama tersebut telah kembali ke Gowa guna melanjutkan pengislaman di Tanah Sulawesi. (Ahmad Amin, 1971)

Beberapa saat setelah Datuk Di Banda dan Datuk Di Tiro kembali ke Gowa, Sultan Abdul Kahir meninggal dunia yaitu pada tanggal 8 Ramadhan 1050 H. beliau kemudian di gantikan oleh putranya Abil khair Sirajuddin 
yang berusia 13 tahun. Memerintah di usia yang masih muda dan kurangnya bimbingan keagamaan menjadikan sultan muda lebih mencintai seni dan budaya. Sesampainya di Bima langkah awal yang di lakukan oleh yang di lakukan oleh datuk raja lelo dan ulama lainya untuk membimbing sultan dan rakyat Bima kembali mendalami ajaran Islam yaitu dengan melakukan pendekatan yang dapat mudah di terima oleh sultan. Para ulama melaksanakan upacara peringatan hari kelahiran nabi Muhammad SAW. Bertepatan pada tanggal 12 Rabiul Awwal yang bertempat di pemukiman para ulama di Ule. Agar sultan berkenan menghadisi upacara maulud yang pertama kali di adakan para ulama merancang berebagai kegiatan yang dapat menarik hati sultan yang menyukai seni tersebut acara peringatan mauled selain di isi dengan Dakwah, tadarus Al-Quran, tablik dan ceramah juga di isi dengan rangkaian atraksi pertunjukan seni islami.

Usaha yang di rintis oleh para ulama ini ternyata membuahkan hasil sesuai yang di harapkan. Sultan dan para pembesar istana berkenan hadir menyaksikan upacara mauled nabi. Gema wahyu ilahi yang di lantunkan oleh para ulama mampu mengetarkan hati Sultan dan dalam jiwanya lahir rasa cinta kepada Al-Qur'an serta bertekad mengamalkan ajaran Agama Islam sesuai tuntunan dalam Al-Qur'an. (Naskah hanta ua pua 2009)

\section{Zikir (Jiki)}

Pada masa kesultanan Bima, seni budaya islam berkembang pesat di daerah Bima Jenis seni musik islam yang sangat digemari oleh masyarakat ialah " jiki " (dzikir), terdiri dari :

- Jiki Molu (dzikir maulud), yang dinyanyikan pada upacara perayaan maulud (ndiha molu). Dinyanyikan oleh penyanyi laki-laki tanpa alunan music.
- Jiki rati, dinyanyikan pada upacara pernikahan, khitanan dan khataman Al Qur'an tanpa diiringi oleh musik.

- Jiki Molu (dzikir maulud), yang dinyanyikan pada upacara perayaan maulud (ndiha molu). Dinyanyikan oleh penyanyi laki-laki tanpa alunan musik.

- Jiki Kapanca, yang dinyanyikan pada upacara pernikahan dan khitananan.

- Jiki Marhaba, pada masa kesultanan setiap perayaan islam antara lain aru raja to'i (idul fitri), aru raja na'e (idul adha) dan upacara Ua Pua selalu dimeriahkan oleh pegelaran seni islam seperti jiki marhaba yang berisi pujian terhadap keagungan Allah SWT dan Nabi Muhammad SAW.

- Jiki tua, dinyanyikan oleh tokoh agama dan adat, diiringi oleh music arubana (rebana).

- Jiki Qasida, sangat digemari di zaman kesultanan. Pada umumnya dilaksanakan setelah upacara tadarru pada malam hari.

- Jiki Hadra, dinyanyikan oleh penyanyi laki-laki diiringi dengan aluran musik arubana. Lazimnya diadakan pada upacara pernikahan. (chunkybrandalz.blogspot.com)

\section{Hadrah}

Hadrah: Merupakan tari tradisional Bima yang berisi puji-pujian kepada Allah SWT. Hadrah yang dimainkan oleh anak-anak maupun orang dewasa. Masuk ke Bima sekitar abad XIV sejak masuknya Islam ke daerah ini. Hadrah Rebana merupakan jenis atraksi yang telah mendapat pengaruh ajaran Islam.

Syair lagu yang dinyanyikan adalah lagu-lagu dalam bahasa Arab dan biasanya mengandung pesan-pesan rohani. Dengan berbekal 3 buah Rebana dan 6 sampai 12 penari, mereka mendendangkan lagu-lagu seperti Marhaban dan lain-lain. Hadrah Rebana biasa digelar pada acara WA'A CO'I (Antar Mahar), Sunatan maupun Khataman Alqur'an. Hingga saat ini Hadrah Rebana telah berkembang pesat sampai 
ke seluruh pelosok. Hal yang menggembirakan adalah Hadrah Rebana ini terus berkembang dan dikreasi oleh seniman di Bima. Dan banyak sekali karya-karya gerakan dan lagu-lagu yang mengiringi permainan Hadrah Rebana ini.

\section{Dali}

Puisi yang di sebut "dali" ini dapat juga di sebut dalil yaitu suatu petuah dan nasehat yang berdasar atas adat dan agama. Dengan tujuan mengingatkan satu sama lain untuk tetap berjalan di jalan yang benar serta selalu mawas diri dalam tiap langkah yang akan di tempuh. Dali terkadang di baca secara bersyair dan kadangkala di nyayikan oleh para penyanyi tradisonal pada acara-acara adat, pernikahan atau pertemuan-pertemuan penting lainnya.

Di bawah ini beberapa contoh dali yang cukup terkenal pada masyarakat Bima yang berisi nasehat dan tuntunan hidup beragama dalam masyarakat.

Pai ka bade ku weki ndai ku ndi ma made ka ngari wau ku ba ndai ku rade, romo ku ndeu di daloa ba ndai

Terjemahan bebas:

"Andai ku tahu kapan raga akan mati

Akan ku gali sendiri kuburku

Cukuplah mandi jenazah yang tak bisa kulakukan sendiri."

Ma nee si bade parakara made

Lampa wa-u di nonto balata au ndi nenti

Ncara si tabi kacobu lu'u ade tabe $2 x$

Terjemahan bebas:

Andai engkau tahu perkara mati

Berjalanlah di titian yang tiada bertepi

Salah melangkah jatuh binasalah kita. 2x

Ma ne'e si bade lampa made

Maru tuta da toro tando di

Kade'e kai mai ama kali mao $2 x$

Terjemahan bebas:

Ketahuilah perkara mati
Kepala menghadap utara badan condong ke barat sambil menunggu datangnya malaikat maut

Ma ne'e sa bade lampa rawi made

doho kaboro di kalubu bura

kade'e kairu parenta jabara'i

terjemahan :

ketahuilah perkara mati

duduk berkumpul di debu putih

mendengarkan perintah malaikat jabara,i

Nahu ra lao ku ele gili ala

Ba nee ku eda lampa mai na made

Pala si made wati bae kai baa de $2 x$

Terjemahan bebas:

Saya akan pergi ketimur menuju gili ala

Karena ingin mengetahui perkara mati

Ternyata datangnya kematian tanpa kita sadari

Kasi toi kai ade mu nasi ti pataha

Ngemo wa'a pu nahu di rasa nci'I kai liro

Ne'e ku eda rasa sinci kai weki $2 x$

Terjemahan bebas :

Berbaik hatilah wahai burung ti pataha

Terbangkanlah saya menuju tanah matahari tenggelam

Sehingga aku bisa melihat tanah penyesalan.

Au ku didi na ina nahu ma made

Na didi ku mbe'e ma umu tolu mba'a

Di karai la were na do laluru woro

Di nente hori na di tada ncai ahera (Achmad, Abdullah. Hal. 201. 1992)

\section{Acara suna ra ndoso (khitanan)}

Ketika seorang anak beranjak dewasa, bagi masyarakat Bima merupakan saat yang tidak kalah sakralnya dengan kelahiran. Proses menjadi dewasa sama halnya dengan momen dimana seorang manusia beralih dunia, meninggalkan masa kanak-kanak yang penuh dengan keceriaan menuju masa remaja yang penuh tanggung jawab bagi diri, keluarga maupun masyarakat.

Dalam adat Bima, proses pendewasaan seorang anak manusia ditandai dengan dua 
macam upacara adat. Upacara adat ini merupakan pengejawantahan syariat Islam yaitu kewajiban untuk melaksanakan khitan bagi lakilaki serta anjuran untuk menamatkan pembelajaran baca Al-Qur'an sebagai penuntun hidup seorang manusia untuk mendapatkan kebahagiaan dunia dan akhirat.

Upacara khitanan dalam adat Mbojo disebut upacara suna ro ndoso (Suna $=$ sunat. $\mathrm{Ndoso}=$ memotong atau meratakan gigi secara simbolis sebelum sunat). Biasanya upacara suna ro ndoso dilakukan ketika anak berumur lima sampai tujuh tahun. Bagi anak perempuan antara dua sampai dengan empat tahun. Upacara khitan bagi anak laki-laki disebut suna. Sedangkan bagi puteri disebut"sa ra so.

Upacara adat suna ra ndoso di laksanakan dengan beberapa tahapan sebagai berikut:

Pertama Mbolo roDampa. Beberapa hari sebelum upacara dilaksanakan, di rumah keluarga yang punya hajat, diadakan mbolo ro dampa atau musyawarah keluarga. Dalam mbolo ro dampa akan diputuskan hari pelaksanaan suna ro ndoso.

Kedua Mada Rawi (Acara Inti). Upacara mada rawi terdiri dari: 1 . Kapanca (penempelan inai) Dilakukan pada malam hari. Pada telapak tangan putra putri yang akan dikhitan ditempelkan kapanca. Dilakukan oleh lima orang tua adat wanita secara bergilir. Seusai upacara kapanca, diadakan upacara "Ngaji tadaru" (Tadarusan). Setelah tadarusan berakhir, maka dilanjutkan qasidah tradisional (Bukan qasidah modern). Acara hiburan dilanjutkan hadrah. Dihalaman rumah dipergelarkan permainan rakyat,seperti mpa'a sila,gantao dan buja kadanda. Tujuan kapanca ialah merupakan peringatan bagi anak, bahwa setelah dikhitan, ia dianggap dewasa. Ia akan bekerja membantu orang tua. Tangan dan kaki yang selama ini tidak biasa bekerja, akan mulai bekerja. Sehingga tangan yang bersih dan halus, akan bercucuran keringat dan darah. 2. Upacara Ndoso dan Compo Sampari Serta Compo Baju. a. Upacara Ndoso. Pagi hari setelah selesai kapanca, akan dilakukan upacara ndoso. Yaitu upacara pemotongan kuku, rambut dan gigi anak yang akan disunat. Gigi si anak sesungguhnya tidak dipotong.Tetapi hanya disuruh menggigit sepotong "haju tatanga" (kayu jarak liar) yang getahnya dapat menguatkan gigi. Acara pemotongan kuku, rambut dan gigi disebut ndoso. Tujuannya ialah untuk membersihkan badan si anak, sesuai dengan perintah agama. b. Upacara Compo Sampari (Pemasangan Keris). Setelah upacara ndoso, dilanjutkan dengan acara compo sampari bagi anak laki-laki. Compo sampari dilakukan oleh seorang tua adat. Ia memasang sampari dirusuk kiri si anak. Diawali bacaan shalawat kepada Nabi. Diiringi dengan musik genda Mbojo dan dimeriahkan dengan pertunjukan kesenian rakyat. Tujuan compo sampari, ialah sebagai peringatan bagi si anak, bahwa ia harus berani mengorbankan jiwa raga demi agama, bangsa dan negara. Sampari yang ia pakai, merupakan senjata dalam mempertahankan kebesaran agama, bangsa dan negara. c. Upacara Compo Baju (Pemasangan Baju) Bagi anak perempuan, setelah upacara ndoso, dilanjutkan dengan upacara compo baju. Yaitu pemasangan baju poro me'e kepada anak yang akan di sa ra so. Dilakukan oleh seorang tua adat wanita. Upacara compo baju dimeriahkan dengan berbagai atraksi kesenian rakyat. Tujuan upacara compo baju, ialah merupakan peringatan bagi si anak, bahwa kalau sudah sa ra so, ia sudah dianggap dewasa. OIeh sebab itu Ia harus menjaga atau melindungi auratnya. Dengan memakai baju, tembe dan todu. (kerudung). Upacara compo baju dimeriahkan dengan atraksi kesenian rakyat, sama dengan upacara compo sampari. 3. Upacara Suna dan Saraso Pada sore han, seusai ndoso dan compo sampari, maka akan 
dilakukan upacara khitan. Khitan bagi anak lakilaki disebut suna. Sedangkan bagi anak wanita disebut saraso. Upacara suna dilakukan oleh seorang tokoh adat pria yang biasa melakukan sunat. Sedangkan saraso dilakukan oleh tokoh adat wanita. Upacara suna dan saraso diiringi dengan irama genda ro no (gendang dan gong). Dilanjutkan dengan pertunjukan permainan rakyat, seperti mpa'a sila, gantao dan buja ka danda.

Khusus bagi anak pria, seusai suna dilanjutkan dengan upacara maka dimana Anak yang baru disunat, turun ke halaman. Ia mencabut kerisnya, sambil melompat, ia mengucapkan tekad dengan suara lantang. Tekad itu berisi pernyataan setia kepada agama. Kalau ada yang memusuhi agama, ia akan siap untuk membelanya.Jadi upacara"maka" tak lain dan pernyataan si anak untuk slap membela agama. Upacara maka diiringi dengan musik genda, no, katongga dan sarone atau silu. (rhakateza.wordpress.com)

\section{Khatam Alquran}

Pada masa lalu, anak-anak dou Mbojo wajib belajar Al Quran. Sehingga disekitar usia tujuh dan sembilan tahun, harus sudah selesai menamatkan pelajaran membaca al Qur'an. Sebagai tanda syukur orang tua, atas keberhasilan anaknya dalam membaca Al Quran, maka akan diadakan upacara yang disebut "Tama" atau khatam Al Qur'an. Upacara tamadimeriahkan dengan berbagai acara. Pada malam hari, diadakan tadarusan, serta hiburan berupa atraksi hadrah, marhaban dan barzanji. Pada upacara itu si anak akan diuji oleh para ahil baca Al Quran. Di hadapan guru ngajinya, ia akan membaca beberapasuratdan Al Quran.ApabilaIakeliru, maka para ulama yang mendengarnya, akan segera menegur. Bapak Guru Ngaji yang mendampingi akan menuntun muridnya. Apabila para ulama dan hadirin menilai, bahwa anak tersebut sudah dapat membaca dengan lancar, maka berarti ia sudah lulus. Guru ngaji bersama orang tua anak akan gembira. Sebaliknya apabila si anak sering melakukan kesalahan, guru ngaji bersama orang tua akan sedih dan malu. Mereka akan mendorong si anak untuk mengulangi lagi pelajaran baca Al Quran. Pada siang hari upacara ini akan dimeriahkan dengan upacára atraksi kesenian rakyat. (rhakateza.wordpress.com)

\section{KESIMPULAN}

Perpaduan antara kebudayaan Islam dan kebudayaan local terjalin indah dalam setiap adat dan budaya yang berkembang dalam masyarakat. hal ini terlihat dari berbagai kebudayaan antaa lain; pertama "Rimpu" yang merupakan busana adat harian tradisional yang berkembang pada masa kesultanan Bima. Sebagai pakaian yang mencerminkan identitas wanita Bima yang sesuai dengan ajaran agama Islam. Upacara memperingatan mauled nabi besar Muhammad SAW di oleh masyarakat Bima di adakan acara Hanta Ua pua. Ketiga Zikir (jiki) kepada Allah yang di lantunkan pada suklus hidup masyarakat. Keempat Hadrah: Merupakan tari tradisional Bima yang berisi pujipujian kepada Allah SWT. Kelima Dali merupakan Puisi yang di sebut "dali" ini dapat juga di sebut dalil yaitu suatu petuah dan nasehat yang berdasar atas adat dan agama. Dengan tujuan mengingatkan satu sama lain untuk tetap berjalan di jalan yang benar serta selalu mawas diri dalam tiap langkah yang akan di tempuh. Keenam Acara khitan dan Khatam Al-qur'an Dalam adat Bima, proses pendewasaan seorang anak manusia ditandai dengan dua macam upacara adat. Upacara adat ini merupakan pengejawantahan syariat Islam yaitu kewajiban untuk melaksanakan khitan bagi lakilaki serta anjuran untuk menamatkan pembelajaran baca Al-Qur'an sebagai penuntun hidup seorang manusia untuk mendapatkan kebahagiaan dunia dan akhirat 


\section{DAFTAR PUSTAKA}

Abdurahman, Dudung. Metode Penelitian Sejarah. Jakarta : Logos. Wacana Ilmu. 1999 Achmad, Abdullah. Kerajaan Bima dan Keberadaanya. Bima : Paguyuban La Mbila. 1992

Amin, Ahmad. Ringkasan Sejarah Bima. Bima: Kantor Kebudayaan Kabupaten Bima. 1971

Effat Al- Sharqawi, Filsafat kebudayaan Islam, (bandung : Penerbit Pustaka. 1986)

Gottschalk, L. Mengerti Sejarah. (1982).Terj. Nugroho Notosusanto. Jakarta: UI Press

Koentjaraningrat, Pengantar Ilmu Antropologi, (Jakarta: Radar Jaya Offset,2000), hlm. 181.

Koentjaraningrat, Kebudayaan, Mentalitas dan Pembangunan, Gramedia Pustaka Utama, Jakarta. 1992

Lamusiah, Siti. Estetika Budaya Rimpu pada Masyarakat Bima " Kajian Religiulitas" Media Bina Ilmiah. 2013.

Majid, Muhammad Saleh. Islamisasi di Kerajaan Bima 1621-1682. Makassar : jurnal IlmuIlmu Budaya Journal Of Cultural Sciences Fakultas Ilmu Budaya Universitas Hasanuddin. 2007

Marwati djoened poesponegoro dan nugroho notosusanto. Sejarah nasional Indonesia III, Jakarta: PN. balai pustaka, 1984.

Sewang, Ahmad M. Islamisasi Kerajaan Gowa Abad XVI Sampai Abad XVII. Jakarta: Yayasan Obor Indonesia. 2005

Sunanto, Musrifah. Sejarah Peradaban Islam Indonesia. Jakarta : PT. RajaGrafindo Persada. 2005

Naskah Upacara adat Hanta ua Pua. Di tteritkan oleh Dinas Kebudayaan dan Pariwisata dengan Majelis Adat Dana Mbojo. 2000

rhakateza.wordpress.com/2011/12/17/mengena l-upacara-adat-mbojo-bima-prosesi-khitanandan-khatam-al-quran.

http://chunkybrandalz.blogspot.com/2013/07/ kesenian-tradisional-bima.html 